\title{
Racial Differences in Hepatocellular Carcinoma Incidence and Risk Factors among a Low Socioeconomic Population
}

\author{
Sylvie Muhimpundu ${ }^{1}$, Rebecca Baqiyyah N. Conway ${ }^{2,3}$, Shaneda Warren Andersen ${ }^{4,5}$, Loren Lipworth ${ }^{1}$, \\ Mark D. Steinwandel ${ }^{6}$, William J. Blot ${ }^{1,6}$, Xiao-Ou Shu ${ }^{1}$ and Staci L. Sudenga ${ }^{1, *}$ \\ 1 Division of Epidemiology, Vanderbilt University Medical Center, Nashville, TN 37232, USA; \\ sylvie.muhimpundu@vanderbilt.edu (S.M.); loren.lipworth@vumc.org (L.L.); \\ william.j.blot@vumc.org (W.J.B.); xiao-ou.shu@vumc.org (X.-O.S.) \\ 2 School of Community and Rural Health, University of Texas Health Science Center at Tyler, \\ Tyler, TX 75708, USA; rebecca.conway@aaepi.org \\ 3 American Academy of Epidemiology, Inc., Tyler, TX 75701, USA \\ 4 Department of Population Health Sciences, School of Medicine and Public Health, \\ University of Wisconsin-Madison, Madison, WI 53706, USA; snandersen@wisc.edu \\ 5 Cancer Prevention and Control, University of Wisconsin Carbone Cancer Center, Madison, WI 53706, USA \\ 6 International Epidemiology Institute, Rockville, MD 20850, USA; mark.d.steinwandel@vumc.org \\ * Correspondence: staci.sudenga@vumc.org
}

check for updates

Citation: Muhimpundu, S.; Conway, R.B.N.; Warren Andersen, S.;

Lipworth, L.; Steinwandel, M.D.; Blot, W.J.; Shu, X.-O.; Sudenga, S.L. Racial Differences in Hepatocellular Carcinoma Incidence and Risk Factors among a Low Socioeconomic Population. Cancers 2021, 13, 3710. https://doi.org/10.3390/cancers13153710

Academic Editor: Donald D. Anthony

Received: 19 April 2021

Accepted: 20 July 2021

Published: 23 July 2021

Publisher's Note: MDPI stays neutral with regard to jurisdictional claims in published maps and institutional affiliations.

Copyright: (c) 2021 by the authors. Licensee MDPI, Basel, Switzerland. This article is an open access article distributed under the terms and conditions of the Creative Commons Attribution (CC BY) license (https:/ / creativecommons.org/licenses/by/ $4.0 /)$.
Simple Summary: Liver cancer incidence in the United States is higher among African Americans compared to White Americans. The determinants of racial disparities in liver cancer incidence are not clear. Using data from White and African Americans from low socioeconomic backgrounds, we compared the prevalence of known liver cancer risk factors by race and assessed factors associated with liver cancer incidence. Understanding liver cancer risk differences can assist prevention strategies that target people at high risk, potentially based on risk factors that differ by race.

Abstract: The purpose of this study was to examine differences in risk factors associated with hepatocellular carcinoma (HCC) among White and African Americans from low socioeconomic backgrounds in the Southern Community Cohort Study (SCCS). The SCCS is a prospective cohort study with participants from the southeastern US. HCC incidence rates were calculated. Multivariable Cox regression was used to calculate HCC-adjusted hazard ratios (aHR) associated with known baseline HCC risk factors for White and African Americans, separately. There were 294 incident HCC. The incidence rate ratio for HCC was higher (IRR = 1.4, 95\%CI: 1.1-1.9) in African Americans compared to White Americans. White Americans saw a stronger association between self-reported hepatitis $\mathrm{C}$ virus $(\mathrm{aHR}=19.24,95 \% \mathrm{CI}$ : 10.58-35.00) and diabetes $(\mathrm{aHR}=3.55,95 \% \mathrm{CI}: 1.96-6.43)$ for the development of HCC compared to African Americans ( $\mathrm{aHR}=7.73,95 \% \mathrm{CI}$ : 5.71-10.47 and aHR = 1.48, 95\%CI: 1.06-2.06, respectively) even though the prevalence of these risk factors was similar between races. Smoking $(\mathrm{aHR}=2.91,95 \% \mathrm{CI}$ : 1.87-4.52) and heavy alcohol consumption $(\mathrm{aHR}=1.59,95 \% \mathrm{CI}$ : 1.19-2.11) were significantly associated with HCC risk among African Americans only. In this large prospective cohort, we observed racial differences in HCC incidence and risk factors associated with HCC among White and African Americans.

Keywords: cancer risk; southeast; racial disparity; SCCS

\section{Introduction}

The incidence of liver cancer has been shown to be increasing over the last decade in many parts of the world including the United States (US) [1-3]. Liver cancer has a 5 -year relative cancer survival rate at $18 \%$, making it the fifth leading cause of cancer death in men and seventh in women in the US in 2016 [4,5]. By 2030, liver cancer is projected to be the third leading cause of cancer-related death in the US [4]. This increasing liver 
cancer incidence and mortality is likely due to the high prevalence of hepatitis $C$ virus (HCV) infections in the "baby boomer" generation (born from 1945 to 1965) [6-8] and the increasing incidence of non-alcoholic fatty liver disease [9].

There are differences in liver cancer incidence and mortality rates by race and ethnicity in the US. Liver cancer incidence rates are higher among African Americans (10.2 per 100,000) compared to White Americans (6.3 per 100,000) [8]. Although liver cancer stage at diagnosis is similar amongst White and African Americans, the 5-year survival in African Americans (21\%) was significantly lower for all stages combined compared to White Americans $(25 \%)[8,10]$. The determinants of racial disparities in liver cancer incidence are not clear. Observed differences in liver cancer trends may reflect race/ethnicity-specific differences in the prevalence of the risk factors for liver cancer. Known liver cancer risk factors include chronic HCV, chronic hepatitis B virus (HBV), non-alcoholic steatohepatitis, alcoholic liver disease, diabetes, and obesity [8,10-15]. Hepatocellular carcinoma (HCC) accounts for $75-85 \%$ of liver cancers [2]. The purpose of this analysis is to examine racial differences in self-reported risk factors (e.g., smoking, alcohol, hepatitis infection, diabetes, and obesity) for HCC incidence among White and African Americans participating in the Southern Community Cohort Study (SCCS), a cohort of individuals with a low socioeconomic background.

\section{Materials and Methods}

\subsection{Study Population}

The SCCS is a prospective study designed to assess the determinants of racial and socioeconomic differences in cancer and other diseases [16,17]. Participants aged 40 to 79 years were recruited across 12 states: Alabama, Arkansas, Florida, Georgia, Kentucky, Louisiana, Mississippi, North Carolina, South Carolina, Tennessee, Virginia, and West Virginia. Cohort recruitment took place between 2002 and 2009. Most participants ( 85\%) were recruited from community health centers $(\mathrm{CHCs})$ in the 12 states and completed a comprehensive baseline interview. The remainder of participants were recruited using stratified random samples of the residents in the 12 states and completed an identical mailed questionnaire. For this analysis, we chose to only include participants recruited from $\mathrm{CHC}$ to focus on persons that were underinsured or uninsured (Figure 1). The baseline survey collected self-reported information on disease determinants such as the participant's demographic factors, history of prior medical conditions, diet, and lifestyle. To be eligible, participants must have been English-speaking, and not under treatment for cancer within the past year (with the exception of non-melanoma skin cancer). The institutional review boards at Vanderbilt University Medical Center and Meharry Medical College approved the study protocol.

\subsection{Hepatocellular Carcinoma (HCC) Incidence}

State Cancer Registries and the National Death Index (NDI) were the primary means of ascertainment of incident HCC diagnoses [16]. SCCS data can be linked with the 12 state cancer registries from which the participants were recruited. It is possible that participants can move out of those twelve states, so we also connected with NDI to identify those additional cases. Liver cancers were identified using the International Classification of Diseases (ICD) 10 code of C22.0 for hepatocellular carcinoma. The participants without HCC were linked to the Social Security Administration (SSA) for determination of current vital status. Cohort member information for those known through SSA to have died (or whose current status is unknown to SSA) was sent to the NDI to ascertain cause (or fact and cause) of death [17]. Cohort data were updated until 31 December 2017. 


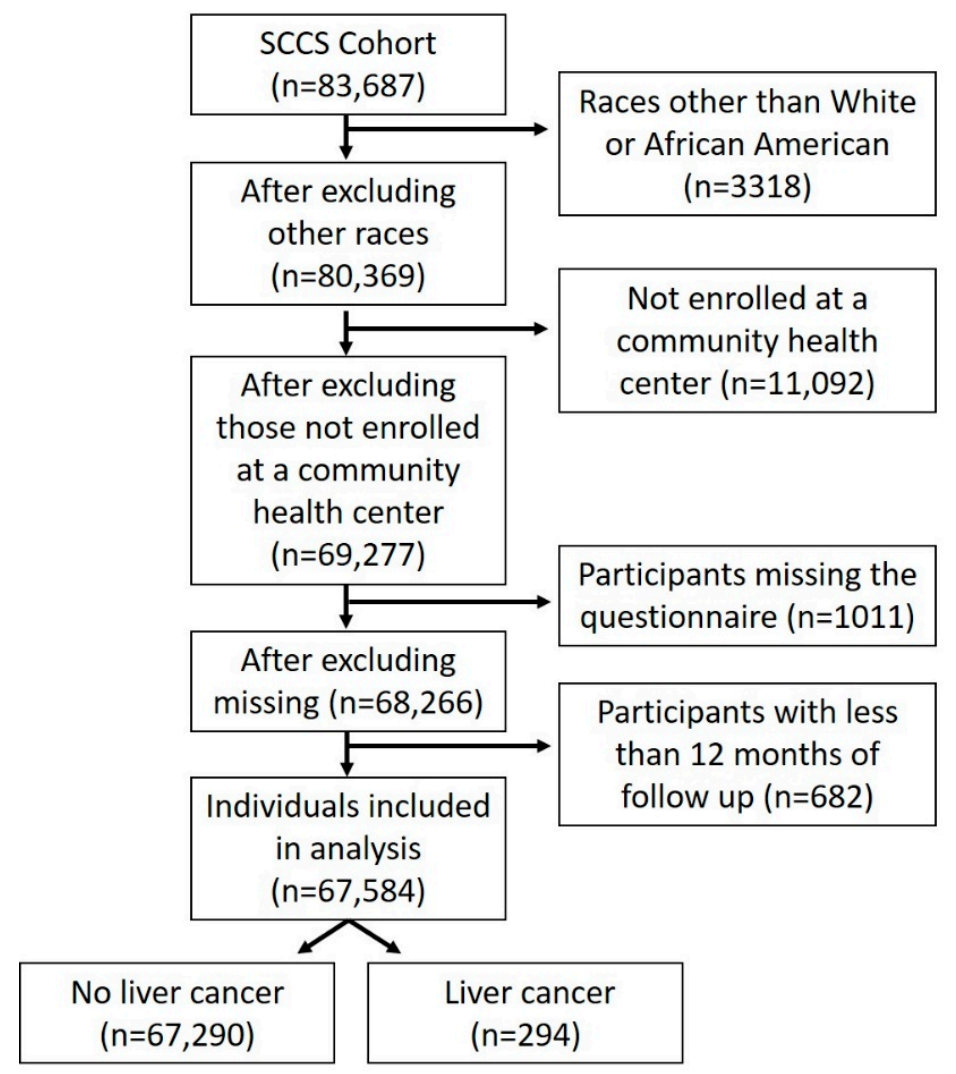

Figure 1. Flow chart of study participants. Exclusion and inclusion criteria are shown.

For participants with an incident HCC diagnosis, follow-up time was calculated from date of cohort enrollment to date of HCC diagnosis for those identified in the cancer registry $(n=270)$ or date of death from HCC for those identified in the NDI $(n=24)$. Follow-up time for participants without an incident HCC diagnosis was calculated from date of cohort enrollment to the date of death or date of vital status.

\subsection{Population for Analysis}

For the current study, we excluded participants with a prior history of liver cancer and those that were missing race and ethnicity (Figure 1). We also excluded participants not from Non-Hispanic White and Non-Hispanic African American ethnic groups $(n=3318)$, participants who were not enrolled at the community health centers $(n=11,092)$, participants that did not have the baseline questionnaire $(n=1011)$, or with a follow-up period of fewer than 12 months ( $n=682)$. After all exclusions, 67,584 participants (72\% Non-Hispanic African Americans and 28\% Non-Hispanic Whites) were included in the analyses. We will refer to Non-Hispanic Whites as White Americans and Non-Hispanic African Americans as African Americans for brevity. Participants self-identified as being African American or White. These self-identified racial categories were not based on genetic characterization. Baseline demographic information that was self-reported in the baseline survey was used to determine risk factors associated with HCC risk.

\subsection{Statistical Analysis}

We used baseline questionnaire responses for our exposures of interest. In this analysis, body mass index (BMI) was calculated as weight in kilograms $(\mathrm{kg})$ over height $\left(\mathrm{m}^{2}\right)$ and categorized as normal $\left(<25 \mathrm{~kg} / \mathrm{m}^{2}\right)$, overweight $\left(25\right.$ to $\left.30 \mathrm{~kg} / \mathrm{m}^{2}\right)$, and obese $\left(\geq 30 \mathrm{~kg} / \mathrm{m}^{2}\right)$. Self-reported age at baseline was analyzed using restricted cubic splines with 3 knots (White American model) or 4 knots (African American model). Participants were asked how often they drank alcohol in the past year and how many drinks they typically had in a day when drinking. We categorized heavy alcohol drinkers as women with on average 
more than one alcoholic drink per day and men with on average more than two alcoholic drinks per day compared to women and men drinking less than that per day [18]. We analyzed alcohol both as a continuous variable and categorical variable and found similar results between the classifications. We report the analyses using a categorical variable for alcohol in this manuscript. Current cigarette smoking status was classified as current, former, and never in our analyses. We assessed cigarette smoking intensity (pack-years) and found similar results to the cigarette smoking status. Hepatitis B virus (HBV), HCV, and diabetes were all based on self-report with the participants being asked "Has a doctor ever told you that you have this virus/disease?". We did not ask if the participant had ever been tested for $\mathrm{HBV}, \mathrm{HCV}$, or diabetes.

The age-adjusted incidence rate was calculated as the number of HCC incident cases divided by the follow-up years, and $95 \%$ confidence intervals (CIs) were estimated. Incidence rate ratios (IRR) and 95\%CIs were also calculated comparing incidence rates between White and African Americans. Cox proportional hazards regression was used to compute hazard ratios (HRs) and 95\%CIs for the incidence of HCC stratified by race. Known HCC risk factors and potential confounders (age, gender, BMI, education, household income, $\mathrm{HBV}, \mathrm{HCV}$, smoking, alcohol, employment status, and diabetes) were identified a priori and assessed within the models. We assessed the interaction between several known HCC risk factors, specifically between diabetes and $\mathrm{HCV}$, and between smoking and alcohol. We also assessed the interaction between the known HCC risk factors and race. The proportionality assumption model using Schoenfeld residuals was assessed and held for the White American model but did not hold for the African American model. When the African American model was stratified by gender, the proportionality assumption was satisfied. Separate unadjusted and adjusted models for African Americans by gender are provided as supplemental tables. All the data analysis was conducted using STATA/IC 15.0.

\section{Results}

\subsection{Study Population}

Overall, there were 294 incident HCC among White $(n=57)$ and African Americans $(n=237)$. Baseline characteristics of the study population by race are shown in Table 1. White and African Americans had similar prevalence of obese participants; $45 \%$ compared to $46 \%$, respectively. Household income <USD 15,000 was more prominent in the African American population (62\%) compared to the White Americans (56\%). Self-reported hepatitis $C$ and hepatitis $B$ infection prevalence was reported more often by White Americans than African Americans. Diabetes prevalence was also similar between White $(21 \%)$ and African Americans (22\%). The prevalence of currently smoking was similar between African Americans (44\%) and White Americans (43\%), but African Americans had a larger proportion that never smoked (36\%) compared to White Americans (31\%). African Americans had a higher prevalence of heavy alcohol drinkers per day (20\%) compared to White Americans $(11 \%)$. Being currently employed was higher among African Americans (38\%) compared to White Americans (33\%). We found that $~ 80 \%$ of both White and African American 65 and older were not currently employed.

\subsection{Incidence Rates}

The overall age-adjusted incidence rate of HCC was 45.5 per 100,000 person-years (95\%CI: 40.3-50.7) among our participants aged 40-79 living in the southeastern United States. African Americans had higher age-adjusted incidence rates of HCC (IR $=49.8$ per 100,000 person-years) compared to White Americans (IR $=33.5$ per 100,000 person-years) with an age-adjusted incidence rate ratio (IRR) of 1.48 (95\%CI 1.1-2.0). 
Table 1. Baseline characteristics of the study population by race.

\begin{tabular}{|c|c|c|}
\hline Characteristics & White Americans & African Americans \\
\hline Number at risk & 18,678 & 48,906 \\
\hline Number of hepatocellular carcinoma cases & 57 & 237 \\
\hline Follow-up time (months; median (IQR)) & $110(89-129)$ & $126(100-145)$ \\
\hline Age at enrollment (years; median (IQR)) & $52(46-59)$ & $50(44-56)$ \\
\hline $40-49$ & 41.6 & 49.8 \\
\hline $50-59$ & 33.5 & 33.7 \\
\hline $60-69$ & 18.7 & 12.6 \\
\hline $70-79$ & 6.3 & 4.1 \\
\hline \multicolumn{3}{|l|}{ Sex, \% } \\
\hline Male & 34.3 & 41.3 \\
\hline Female & 65.7 & 58.7 \\
\hline \multicolumn{3}{|l|}{ BMI category, \% } \\
\hline Normal & 25.8 & 24.5 \\
\hline Overweight & 28.6 & 28.8 \\
\hline Obese & 44.7 & 45.7 \\
\hline Missing & 0.8 & 1.1 \\
\hline \multicolumn{3}{|l|}{ Education, \% } \\
\hline$<$ High School & 29.0 & 33.2 \\
\hline High School & 35.4 & 35.2 \\
\hline$>$ High School & 35.6 & 31.6 \\
\hline Missing & 0.0 & 0.0 \\
\hline \multicolumn{3}{|l|}{ Household income, \% } \\
\hline$<$ USD 15,000 & 56.0 & 61.8 \\
\hline USD 15,000-49,999 & 34.3 & 33.5 \\
\hline$>$ USD 50,000 & 8.6 & 3.6 \\
\hline Missing & 1.1 & 1.1 \\
\hline \multicolumn{3}{|l|}{ Self-reported hepatitis B virus infection, $\%$} \\
\hline No & 95.7 & 97.2 \\
\hline Yes & 2.0 & 1.5 \\
\hline Missing & 2.4 & 1.3 \\
\hline \multicolumn{3}{|l|}{ Self-reported hepatitis C virus infection, $\%$} \\
\hline No & 92.6 & 95.6 \\
\hline Yes & 5.0 & 3.1 \\
\hline Missing & 2.4 & 1.3 \\
\hline \multicolumn{3}{|l|}{ Diabetes, \% } \\
\hline No & 79.0 & 77.8 \\
\hline Yes & 20.7 & 22.0 \\
\hline Missing & 0.3 & 1.3 \\
\hline
\end{tabular}


Table 1. Cont.

\begin{tabular}{|c|c|c|}
\hline Characteristics & White Americans & African Americans \\
\hline \multicolumn{3}{|l|}{$\begin{array}{l}\text { Among those with diabetes, use of } \\
\text { prescription diabetes medication, } \%\end{array}$} \\
\hline No & 19.4 & 13.3 \\
\hline Yes & 80.6 & 86.6 \\
\hline Missing & 0.0 & 0.01 \\
\hline $\begin{array}{l}\text { Among those with diabetes, number of years } \\
\text { with diabetes (years, median (IQR)) }\end{array}$ & $6(2-12)$ & $7(2-14)$ \\
\hline \multicolumn{3}{|l|}{ Insurance coverage, $\%$} \\
\hline No & 43.3 & 43.2 \\
\hline Yes & 56.0 & 56.3 \\
\hline Missing & 0.7 & 0.6 \\
\hline \multicolumn{3}{|l|}{ Use of aspirin, $\%^{a}$} \\
\hline No & 85.3 & 88.2 \\
\hline Yes & 14.3 & 11.5 \\
\hline Missing & 0.4 & 0.4 \\
\hline \multicolumn{3}{|l|}{ Use of over-the-counter pain-relievers, ${ }^{a} \%$} \\
\hline No & 78.0 & 84.0 \\
\hline Yes & 21.6 & 15.6 \\
\hline Missing & 0.4 & 0.4 \\
\hline \multicolumn{3}{|l|}{ Use of prescription pain-relievers, ${ }^{\text {a } \%}$} \\
\hline No & 93.5 & 96.6 \\
\hline Yes & 6.1 & 3.1 \\
\hline Missing & 0.4 & 0.3 \\
\hline \multicolumn{3}{|l|}{ Cigarette smoking status, $\%$} \\
\hline Never & 30.8 & 36.4 \\
\hline Former & 25.6 & 19.2 \\
\hline Current & 43.4 & 44.2 \\
\hline Missing & 0.2 & 0.2 \\
\hline \multicolumn{3}{|l|}{ Heavy alcohol drinkers, $\mathrm{b} \%$} \\
\hline No & 87.1 & 78.6 \\
\hline Yes & 11.7 & 20.4 \\
\hline Missing & 1.2 & 1.0 \\
\hline \multicolumn{3}{|l|}{ Currently employed, \% } \\
\hline No & 66.8 & 61.9 \\
\hline Yes & 32.5 & 37.5 \\
\hline Missing & 0.8 & 0.7 \\
\hline
\end{tabular}


Table 1. Cont.

\begin{tabular}{|c|c|c|}
\hline Characteristics & White Americans & African Americans \\
\hline \multicolumn{3}{|c|}{ Laborer, including construction worker, ${ }^{\mathrm{c}} \%$} \\
\hline No & 88.9 & 87.5 \\
\hline Yes & 10.4 & 11.8 \\
\hline Missing & 0.8 & 0.7 \\
\hline \multicolumn{3}{|l|}{ Dry cleaning, $\mathrm{d} \%$} \\
\hline No & 98.7 & 98.3 \\
\hline Yes & 0.6 & 1.0 \\
\hline Missing & 0.8 & 0.7 \\
\hline \multicolumn{3}{|l|}{ Farming, $\mathrm{d} \%$} \\
\hline No & 93.3 & 94.8 \\
\hline Yes & 5.9 & 4.6 \\
\hline Missing & 0.8 & 0.6 \\
\hline \multicolumn{3}{|l|}{ Chemical production or use, $\mathrm{d} \%$} \\
\hline No & 96.0 & 97.2 \\
\hline Yes & 3.2 & 2.1 \\
\hline Missing & 0.8 & 0.7 \\
\hline
\end{tabular}

Abbreviations: IQR, interquartile range; USD, US dollar; BMI, body mass index; prescription pain relievers include Celebrex, Vioxx, or Bextra. ${ }^{a}$ In the past year, the participant has taken the medication at least two times per week; ${ }^{b}$ heavy alcohol drinkers were defined as more than one drink per day on average for females and more than two drinks on average for males; ${ }^{\mathrm{c}}$ laborer, including construction worker: whether they worked as laborers for the longest period of their adult life; ${ }^{\mathrm{d}}$ farming, dry cleaning, chemical production or use: whether they worked in the corresponding field for more than 10 years.

\subsection{Cox Regression Model}

Tables 2 and 3 show the multivariable-adjusted hazard ratios of HCC by race. After adjusting for potential risk factors and confounders with age included using restricted cubic splines, males were more likely to develop HCC than females in both African Americans (adjusted hazard ratio (aHR) $=2.05,95 \% \mathrm{CI}: 1.50-2.80)$ and White Americans $(\mathrm{aHR}=2.83,95 \% \mathrm{CI}: 1.58-5.07) . \mathrm{HCV}$ was significantly associated with HCC in both racial groups, with a more pronounced association among White Americans ( $\mathrm{aHR}=19.24,95 \% \mathrm{CI}$ : 10.58-35.00) than African Americans ( $\mathrm{aHR}=7.73,95 \% \mathrm{CI}$ : 5.71-10.47). In a combined race model assessing race and $\mathrm{HCV}$ and $\mathrm{HCC}$, the interaction between race and $\mathrm{HCV}$ was not significant $(p=0.08)$. Similarly, diabetes was significantly associated with HCC in both racial groups, but with a stronger association among White Americans $(\mathrm{aHR}=3.55$, 95\%CI: 1.96-6.43) than African Americans (aHR $=1.48,95 \% \mathrm{CI}$ : 1.06-2.06). The interaction between race and diabetes in a combined race model assessing race and diabetes and HCC was significant $(p=0.01)$. Among African Americans, current cigarette smokers $(\mathrm{aHR}=2.91,95 \% \mathrm{CI}: 1.87-4.52)$ had an increased risk of HCC compared to never smokers, but smoking was not significantly associated with HCC risk among White Americans. In a combined race model assessing race and smoking and HCC, the interaction between current smokers and race was significant $(p=0.04)$. Furthermore, heavy alcohol consumption was significantly associated with HCC risk in African Americans only $(\mathrm{aHR}=1.59,95 \% \mathrm{CI}$ : 1.19-2.11). BMI was not significantly associated with HCC in White Americans and obese African Americans were at a lower risk for HCC (aHR = 0.65, 95\%CI: 0.45-0.95). 
Table 2. Univariate and multivariable hazard ratios (HR) and $95 \%$ confidence intervals $(95 \% \mathrm{CI})$ for risk factors associated with hepatocellular carcinoma (HCC) incidence among African Americans.

\begin{tabular}{|c|c|c|c|c|}
\hline & \multirow{2}{*}{ No Incident Cancer } & \multirow{2}{*}{ Incident HCC } & \multirow{2}{*}{$\begin{array}{c}\text { Univariate } \\
\text { HR }(95 \% C I)\end{array}$} & \multirow{2}{*}{$\begin{array}{c}\text { Multivariable }^{\mathrm{a}} \\
\text { HR }(95 \% \mathrm{CI})\end{array}$} \\
\hline & & & & \\
\hline \multicolumn{5}{|l|}{ Age at enrollment ${ }^{b}$} \\
\hline 40 & 2644 & 6 & $0.19(0.10-0.38)$ & $0.23(0.12-0.46)$ \\
\hline 46 & 2348 & 10 & $0.72(0.63-0.84)$ & $0.71(0.61-0.82)$ \\
\hline 50 (Median) & 2203 & 15 & 1.00 (Ref.) & 1.00 (Ref.) \\
\hline 53 & 1911 & 11 & $1.04(0.90-1.20)$ & $1.12(0.97-1.31)$ \\
\hline 68 & 422 & 0 & $0.86(0.58-1.28)$ & $1.75(1.14-2.68)$ \\
\hline \multicolumn{5}{|l|}{ Sex } \\
\hline Female & 28,624 & 67 & 1.00 (Ref.) & 1.00 (Ref.) \\
\hline Male & 20,045 & 170 & $3.81(2.87-5.06)$ & $2.05(1.50-2.80)$ \\
\hline \multicolumn{5}{|l|}{ BMI category } \\
\hline Normal & 11,888 & 96 & 1.00 (Ref.) & 1.00 (Ref.) \\
\hline Overweight & 13,994 & 85 & $0.72(0.54-0.96)$ & $0.98(0.72-1.32)$ \\
\hline Obese & 22,272 & 56 & $0.30(0.21-0.41)$ & $0.65(0.45-0.95)$ \\
\hline \multicolumn{5}{|l|}{ Education } \\
\hline$<$ High School & 16,136 & 91 & 1.00 (Ref.) & 1.00 (Ref.) \\
\hline High School & 17,128 & 91 & $0.92(0.69-1.23)$ & $1.06(0.78-1.43)$ \\
\hline$>$ High School & 15,395 & 55 & $0.59(0.42-0.83)$ & $0.78(0.55-1.11)$ \\
\hline \multicolumn{5}{|l|}{ Household income } \\
\hline$<$ USD 15,000 & 30,061 & 177 & 1.00 (Ref.) & 1.00 (Ref.) \\
\hline USD 15,000-49,999 & 16,325 & 56 & $0.55(0.40-0.74)$ & $0.84(0.61-1.17)$ \\
\hline >USD 50,000 & 1746 & 3 & $0.27(0.09-0.85)$ & $0.53(0.17-1.70)$ \\
\hline \multicolumn{5}{|l|}{ Hepatitis B } \\
\hline No & 47,335 & 223 & 1.00 (Ref.) & 1.00 (Ref.) \\
\hline Yes & 714 & 9 & $2.78(1.43-5.42)$ & $1.82(0.93-3.56)$ \\
\hline \multicolumn{5}{|l|}{ Hepatitis C } \\
\hline No & 46,578 & 168 & 1.00 (Ref.) & 1.00 (Ref.) \\
\hline Yes & 1471 & 64 & 13.07 (9.79-17.44) & $7.73(5.71-10.47)$ \\
\hline \multicolumn{5}{|l|}{ Diabetes } \\
\hline No & 37,850 & 182 & 1.00 (Ref.) & 1.00 (Ref.) \\
\hline Yes & 10,720 & 55 & $1.17(0.87-1.59)$ & $1.48(1.06-2.06)$ \\
\hline \multicolumn{5}{|l|}{ Cigarette smoking status } \\
\hline Never & 17,792 & 28 & 1.00 (Ref.) & 1.00 (Ref.) \\
\hline Former & 9364 & 35 & $2.44(1.48-4.01)$ & $1.45(0.87-2.42)$ \\
\hline Current & 21,424 & 174 & $5.37(3.61-8.01)$ & $2.91(1.87-4.52)$ \\
\hline
\end{tabular}


Table 2. Cont.

\begin{tabular}{|c|c|c|c|c|}
\hline & \multirow{2}{*}{ No Incident Cancer } & \multirow{2}{*}{ Incident HCC } & Univariate & Multivariable $^{a}$ \\
\hline & & & HR (95\%CI) & HR (95\%CI) \\
\hline \multicolumn{5}{|c|}{ Heavy alcohol drinker ${ }^{c}$} \\
\hline No & 38,275 & 146 & 1.00 (Ref.) & 1.00 (Ref.) \\
\hline Yes & 9891 & 91 & $2.49(1.92-3.24)$ & $1.59(1.19-2.11)$ \\
\hline \multicolumn{5}{|c|}{ Currently employed } \\
\hline No & 30,084 & 182 & 1.00 (Ref.) & 1.00 (Ref.) \\
\hline Yes & 18,264 & 55 & $0.45(0.33-0.61)$ & $0.73(0.53-0.99)$ \\
\hline
\end{tabular}

Abbreviations: HR: hazard ratio, BMI: body mass index. ${ }^{a}$ Multivariable model is adjusted for all other variables in the table; ${ }^{b}$ self-reported age at baseline was analyzed using restricted cubic splines with 4 knots. We present number of cases with and without HCC at each of those knots. Not all ages are presented in the table; ${ }^{c}$ heavy alcohol drinkers were defined as more than one drink on average for females and more than two drinks on average for males per day over the past year.

Table 3. Univariate and multivariable hazard ratios (HR) and $95 \%$ confidence intervals (95\%CI) for risk factors associated with hepatocellular carcinoma (HCC) incidence among White Americans.

\begin{tabular}{|c|c|c|c|c|}
\hline & \multirow{2}{*}{ No Incident Cancer } & \multirow{2}{*}{ Incident HCC } & \multirow{2}{*}{$\begin{array}{c}\text { Univariate } \\
\text { HR }(95 \% C I)\end{array}$} & \multirow{2}{*}{$\begin{array}{c}\text { Multivariable }^{\text {a }} \\
\text { HR }(95 \% \mathrm{CI})\end{array}$} \\
\hline & & & & \\
\hline \multicolumn{5}{|l|}{ Age at enrollment ${ }^{b}$} \\
\hline 42 & 763 & 0 & $0.52(0.26-1.05)$ & $0.50(0.24-1.04)$ \\
\hline 52 (Median) & 665 & 6 & 1.00 (Ref.) & 1.00 (Ref.) \\
\hline 66 & 313 & 1 & $0.64(0.32-1.30)$ & $1.44(0.69-3.01)$ \\
\hline \multicolumn{5}{|l|}{ Sex } \\
\hline Female & 12,248 & 19 & 1.00 (Ref.) & 1.00 (Ref.) \\
\hline Male & 6373 & 38 & $4.24(2.44-7.35)$ & $2.83(1.58-5.07)$ \\
\hline \multicolumn{5}{|l|}{ BMI category } \\
\hline Normal & 4806 & 21 & 1.00 (Ref.) & 1.00 (Ref.) \\
\hline Overweight & 5336 & 12 & $0.51(0.25-1.03)$ & $0.52(0.25-1.07)$ \\
\hline Obese & 8325 & 24 & $0.65(0.36-1.16)$ & $0.79(0.41-1.53)$ \\
\hline \multicolumn{5}{|l|}{ Education } \\
\hline$<$ High School & 5395 & 20 & 1.00 (Ref.) & 1.00 (Ref.) \\
\hline High School & 6593 & 16 & $0.66(0.34-1.27)$ & $0.67(0.35-1.31)$ \\
\hline > High School & 6632 & 21 & $0.87(0.47-0)$ & $0.82(0.42-1.59)$ \\
\hline \multicolumn{5}{|l|}{ Household income } \\
\hline$<$ USD 15,000 & 10,423 & 40 & 1.00 (Ref.) & 1.00 (Ref.) \\
\hline USD 15,000-49,999 & 6393 & 10 & $0.39(0.20-0.79)$ & $0.54(0.26-1.12)$ \\
\hline$>$ USD 50,000 & 1601 & 7 & $1.14(0.51-2.54)$ & $1.88(0.74-4.75)$ \\
\hline \multicolumn{5}{|l|}{ Hepatitis B } \\
\hline No & 17,817 & 53 & 1.00 (Ref.) & 1.00 (Ref.) \\
\hline Yes & 361 & 4 & $3.83(1.39-10.58)$ & $1.66(0.58-4.73)$ \\
\hline
\end{tabular}


Table 3. Cont.

\begin{tabular}{|c|c|c|c|c|}
\hline & \multirow{2}{*}{ No Incident Cancer } & \multirow{2}{*}{ Incident HCC } & \multirow{2}{*}{$\begin{array}{c}\text { Univariate } \\
\text { HR }(95 \% C I)\end{array}$} & \multirow{2}{*}{$\begin{array}{c}\text { Multivariable }^{\text {a }} \\
\text { HR }(95 \% \mathrm{CI})\end{array}$} \\
\hline & & & & \\
\hline \multicolumn{5}{|l|}{ Hepatitis C } \\
\hline No & 17,275 & 28 & 1.00 (Ref.) & 1.00 (Ref.) \\
\hline Yes & 903 & 29 & $22.41(13.33-37.67)$ & $19.24(10.58-35.00)$ \\
\hline \multicolumn{5}{|l|}{ Diabetes } \\
\hline No & 14,714 & 35 & 1.00 (Ref.) & 1.00 (Ref.) \\
\hline Yes & 3849 & 22 & $2.61(1.53-4.45)$ & $3.55(1.96-6.43)$ \\
\hline \multicolumn{5}{|c|}{ Cigarette smoking status } \\
\hline Never & 5739 & 11 & 1.00 (Ref.) & 1.00 (Ref.) \\
\hline Former & 4770 & 12 & $1.37(0.60-3.10)$ & $0.87(0.38-2.00)$ \\
\hline Current & 8069 & 34 & $2.35(1.19-4.65)$ & $1.23(0.56-2.71)$ \\
\hline \multicolumn{5}{|c|}{ Heavy alcohol drinker ${ }^{c}$} \\
\hline No & 16,234 & 42 & 1.00 (Ref.) & 1.00 (Ref.) \\
\hline Yes & 2164 & 15 & $2.53(1.40-4.56)$ & $1.80(0.95-3.42)$ \\
\hline \multicolumn{5}{|l|}{ Currently employed } \\
\hline No & 12,438 & 38 & 1.00 (Ref.) & 1.00 (Ref.) \\
\hline Yes & 6043 & 19 & $0.96(0.55-1.67)$ & $1.68(0.90-3.14)$ \\
\hline
\end{tabular}

Abbreviations: HR: hazard ratio, BMI: body mass index. ${ }^{a}$ Multivariable model is adjusted for all other variables in the table; ${ }^{\mathrm{b}}$ self-reported age at baseline was analyzed using restricted cubic splines with 3 knots. We present number of cases with and without HCC at each of those knots. Not all ages are presented in the table; ${ }^{\mathrm{c}}$ heavy alcohol drinkers were defined as more than one drink on average for females and more than two drinks on average for males per day over the past year.

\section{Discussion}

In this large ongoing cohort study of mostly low socioeconomic White and African American participants living in the southeastern US, we found racial differences in selfreported risk factors associated with HCC incidence. While the prevalence of several known risk factors for HCC were generally similar between White and African Americans, HCC incidence rates were higher among African Americans compared to White Americans. White Americans saw a greater effect between self-reported HCV and diabetes for the development of HCC compared to African Americans, while smoking and alcohol use were significantly associated with HCC risk among African Americans only.

We found that males had a higher incidence of HCC than females in both White and African Americans. Gender differences in HCC incidence may reflect the higher prevalence of HCC risk factors in males than females (Table S3). An additional possible explanation for the observed gender disparity in HCC incidence is the higher estrogen levels in females compared to males. Studies suggest that estrogen reduces HCC by inhibiting the production of interleukin-6 (IL-6), a multifunctional cytokine that may be causal or contributory to HCC [19-21].

Previous studies have shown that diabetes is associated with a two- to three-fold increased risk of HCC and other conditions such as chronic non-alcoholic liver disease [22]. These findings corroborate with our results; diabetes had a positive association with HCC. The association was statistically significant in both White and African Americans but was stronger in White Americans compared to African Americans. Although the prevalence of self-reported diabetes at baseline was higher in African Americans $(22.0 \%, 95 \% \mathrm{CI}$ $21.6-22.4 \%)$ compared to White Americans $(20.7 \%, 95 \%$ CI $20.1-21.3 \%)$, the prevalence of self-reported diabetes was greater in White Americans (38.6\%, 95\%CI 25.9-51.2\%) with an incident HCC compared with their counterpart in African Americans $(23.2 \%, 95 \% \mathrm{CI}$ 17.8-28.6\%). The difference in diabetes association with HCC between White and African 
Americans might be explained by the higher proportion of White Americans with both $\mathrm{HCV}$ and diabetes at baseline (14.0\%) that developed HCC compared to African Americans $(6.8 \%)$ with both HCV and diabetes that developed HCC. However, this interaction was not statistically significant in our models. A previous study has found that there is a synergism on HCC risk among diabetes, chronic HBV / HCV infection, and alcohol consumption; presumably accelerating the process of fibrosis and progression to cirrhosis. The odds for $\mathrm{HCC}$ in patients with diabetes decreases when the patients do not have HBV, HCV, and alcoholic liver diseases [23].

Our findings with respect to both self-reported hepatitis and diabetes indicate that neither of these risk factors account for the observed higher incidence of HCC among African Americans than White Americans in the SCCS population. Indeed, both illnesses were stronger determinants of risk among White Americans than African Americans, so that the elevated HCC risk among African Americans than White Americans occurs predominantly among those not affected by HCV or diabetes. Determinants of this disparity remain to be quantified.

A number of studies have reported an association between BMI and an increase in HCC risks [24-26]. A meta-analysis found that compared to individuals with normal weight (BMI 18.5-24.9 $\mathrm{kg} \mathrm{m}^{-2}$ ), those who were overweight (BMI 25-30 $\mathrm{kg} \mathrm{m}^{-2}$ ) or obese $\left(\geq 30 \mathrm{~kg} \mathrm{~m}^{-2}\right.$ ) had a $17 \%$ and $89 \%$, respectively, increased risk of HCC [24]. We found no association between BMI and HCC risk in White or overweight African Americans in adjusted models. Obese African Americans were at a lower risk for HCC than normal weight African Americans. In adjusted models, the interaction between BMI and alcohol was assessed and was not significantly associated with liver cancer incidence in both White and African Americans. Additionally, the interaction between BMI and diabetes was not significantly associated with liver cancer incidence in both White and African Americans. In our stratified analyses by sex among African Americans, the association between BMI and HCC risk was not significant in males but was for females. Differences in results may be due to BMI not capturing the association between obesity and HCC [24]. In one study, visceral fat and not BMI was associated with HCC risk [27]. The Multiethnic Cohort Study also found no association between HCC risk and obesity among African Americans but did find an association among White American males [26]. The study suggested that the previously reported relationship between BMI and the risk of HCC was mediated by visceral fat accumulation which is directly associated with hepatocarcinogenesis rather than BMI [27]. African Americans have been shown to have a lower amount of visceral fat compared to White Americans [28]. Visceral abdominal adiposity was also associated with increased risk for hepatic steatosis and fibrosis in HCV as well as non-alcoholic fatty liver disease [27]. Alternatively, liver disease and cancer can cause a decrease in appetite and weight loss prior to diagnosis. To assesses reverse causality between BMI and liver cancer, analyses were stratified by participants with less than or equal to five years or greater than five years of follow-up time (data not shown). There were no significant differences between BMI and liver cancer by follow-up time and race.

Alcohol [29,30] and cigarette smoking [11,31] are well established risk factors for HCC. In this study, cigarette smoking and alcohol consumption were associated with HCC among African Americans but not White Americans in adjusted models, although the interaction term between smoking and alcohol was not significant for White or African Americans. Cigarette smoking status was similar between White and African Americans at baseline, while alcohol consumption was higher among African Americans compared to White Americans. Alcohol and smoking were significantly associated with liver cancer in univariate models among White Americans but was no longer significant after adjusting for other covariates. The hazard ratios were similar between White and African Americans for smoking and alcohol. It is possible that models were underpowered among White Americans since there were 57 incident liver cancer cases. Smoking cessation and reduction in alcohol consumption could reduce the occurrence of HCC. 
In our study, self-reported HCV infection at baseline was associated with a 19-fold increased HCC incidence in White Americans and 8-fold increase in African Americans in adjusted models. The overall self-reported HCV prevalence among White Americans was $5.0 \%$ (95\%CI 4.7-5.3\%) and 3.1\% (95\%CI 3.0-3.3\%) among African Americans. However, among White Americans that developed HCC, 50.9\% (95\%CI 37.9-63.9\%) were infected with $\mathrm{HCV}$ at baseline compared to 27.0\% (95\%CI 21.4-32.7\%) among African Americans. Despite the recruitment of both White and African Americans from community health center settings, it is possible that fewer African American SCCS participants were tested for HCV compared to White SCCS participants as HCV was self-reported in our cohort. NHANES data reporting HCV prevalence ratios comparing African Americans to White Americans by state show higher HCV prevalence among African Americans compared to White Americans in each of the 12 states included in the SCCS except for Mississippi [32]. Although the seroprevalence being reported is among the entire population and not stratified by SES. At the time of enrollment, guidelines for HCV testing [33] in the US included a 1-time screening in all adults born between 1945 to 1965 and 80\% of the SCCS population would qualify for this screening. The SCCS did not assess HCV testing in this population and therefore we cannot make conclusions without testing and diagnosis information. Additionally, we do not have HCV treatment history available on these participants.

HBV infection was not associated with an increased hazard for liver cancer after adjusting for other covariates in both White and African Americans. HBV self-reported seroprevalence was low in the SCCS and less than $1 \%$ of those that reported HBV infection developed liver cancer. There were 117 participants who reported both an HBV and HCV infection in the SCCS cohort and only 4 of these developed liver cancer. An interaction analysis between $\mathrm{HBV}$ and $\mathrm{HCV}$ was not statistically significant in both White and African Americans. The Center for Disease Control reports that $15 \%$ of liver cancers are attributable to $\mathrm{HBV}$ infection in the US and HBV infection disproportionality affects Asian Americans and Pacific Islanders [34].

Our study has several strengths and limitations. The strength of this study includes its prospective design, and the use of a large data set from an ethnically diverse and low socioeconomic status cohort. Ascertainment of HCC was believed to be relatively complete via linkage with cancer registries in each of the 12 recruitment states and with the NDI. The study also considered most known and suspected HCC risk factors. Our results should also be read in the context of certain limitations. There were a small number of HCC cases among White Americans which led to wide confidence intervals and there needs to be caution in the interpretation of some of our findings. Several baseline characteristics were self-reported and subjected our analysis to recall errors. Hepatitis B and C were self-reported at baseline and there was no information on the treatment of these diseases. $\mathrm{HCV}$ risk factors such as sexual partners and injection drug use were also not captured within the questionnaire. Our questionnaire did not capture information on liver diseases such as cirrhosis, liver fibrosis, and non-alcoholic fatty liver disease and there could be racial differences in disease severity that could affect progression to HCC.

\section{Conclusions}

In conclusion, we have demonstrated that the prevalence and strength of the association with HCC for several known risk factors differed by race. The major risk factors of $\mathrm{HCV}$, diabetes and obesity, seem weaker (or in the case of obesity, non-existent) among African Americans, suggesting that other factors account for the higher incidence rates of HCC among African Americans. It also is possible that other factors, such as genetic susceptibility, vary between White and African Americans and help explain the risk differentials. Further studies are needed to better understand the associations observed in this study and to identify factors that contribute to the racial differences in HCC risk. 
Supplementary Materials: The following are available online at https: / www.mdpi.com/article/ 10.3390/cancers13153710/s1, Table S1: Univariate and multivariable hazard ratios (HR) and 95\% confidence intervals $(95 \% \mathrm{CI})$ for risk factors associated with liver cancer incidence among African American females. Table S2: Univariate and multivariable hazard ratios (HR) and 95\% confidence intervals $(95 \% \mathrm{CI})$ for risk factors associated with liver cancer incidence among African American males. Table S3: Baseline characteristics of the study population by race and sex.

Author Contributions: Planning and conducting the study: S.M., S.W.A., L.L., M.D.S., W.J.B., X.-O.S., S.L.S.; interpreting the data: S.M., R.B.N.C., S.W.A., L.L., M.D.S., W.J.B., X.-O.S., S.L.S.; drafting the manuscript: S.M., S.L.S.; manuscript review/edit: S.M., R.B.N.C., S.W.A., L.L., M.D.S., W.J.B., X.-O.S., S.L.S. All authors have read and agreed to the published version of the manuscript.

Funding: The Southern Community Cohort Study was supported by the NIH (grant numbers R01 CA092447 and U01 CA202979). Drs. Warren Anderson (R00 CA207848) and Sudenga (K07 CA225404) are supported by the National Cancer Institute.

Institutional Review Board Statement: The study was conducted according to the guidelines of the Declaration of Helsinki and approved by the Institutional Review Board of Vanderbilt University Medical Center and Meharry Medical College (protocol code 010345 and date of approval 2001).

Informed Consent Statement: Informed consent was obtained from all subjects involved in the study.

Data Availability Statement: Restrictions apply to the availability of these data. Data were obtained from the Southern Community Cohort Study and are available at https:/ / www.southerncommunitystudy.org/ (accessed on 11 December 2018) with the permission from the Southern Community Cohort Study.

Acknowledgments: Data on SCCS cancer cases used in this publication were provided by the Alabama Statewide Cancer Registry; Kentucky Cancer Registry, Lexington, KY; Tennessee Department of Health, Office of Cancer Surveillance; Florida Cancer Data System; North Carolina Central Cancer Registry, North Carolina Division of Public Health; Georgia Comprehensive Cancer Registry; Louisiana Tumor Registry; Mississippi Cancer Registry; South Carolina Central Cancer Registry; Virginia Department of Health, Virginia Cancer Registry; Arkansas Department of Health, Cancer Registry, 4815 W. Markham, Little Rock, AR 72205. The Arkansas Central Cancer Registry is fully funded by a grant from the National Program of Cancer Registries, Centers for Disease Control and Prevention (CDC). Data on SCCS cancer cases from Mississippi were collected by the Mississippi Cancer Registry, which participates in the National Program of Cancer Registries (NPCR) of the Centers for Disease Control and Prevention (CDC). Cancer data for SCCS cancer cases from West Virginia have been provided by the West Virginia Cancer Registry. Research reported in this publication was supported by the National Cancer Institute of the National Institutes of Health. The content is solely the responsibility of the authors and does not necessarily represent the official views of the National Institutes of Health.

Conflicts of Interest: The authors declare no conflict of interest. The funders had no role in the design of the study; in the collection, analyses, or interpretation of data; in the writing of the manuscript, or in the decision to publish the results.

\section{References}

1. Momin, B.R.; Pinheiro, P.S.; Carreira, H.; Li, C.; Weir, H.K. Liver cancer survival in the United States by race and stage (2001-2009): Findings from the CONCORD-2 study. Cancer 2017, 123 (Suppl. S24), 5059-5078. [CrossRef] [PubMed]

2. Bray, F.; Ferlay, J.; Soerjomataram, I.; Siegel, R.L.; Torre, L.A.; Jemal, A. Global cancer statistics 2018: GLOBOCAN estimates of incidence and mortality worldwide for 36 cancers in 185 countries. CA Cancer J. Clin. 2018, 68, 394-424. [CrossRef] [PubMed]

3. Torre, L.A.; Siegel, R.L.; Ward, E.M.; Jemal, A. Global Cancer Incidence and Mortality Rates and Trends-An Update. Cancer Epidemiol. Biomark. Prev. 2016, 25, 16-27. [CrossRef] [PubMed]

4. Rahib, L.; Smith, B.D.; Aizenberg, R.; Rosenzweig, A.B.; Fleshman, J.M.; Matrisian, L.M. Projecting cancer incidence and deaths to 2030: The unexpected burden of thyroid, liver, and pancreas cancers in the United States. Cancer Res. 2014, 74, $2913-2921$. [CrossRef]

5. Siegel, R.L.; Miller, K.D.; Jemal, A. Cancer statistics, 2019. CA Cancer J. Clin. 2019, 69, 7-34. [CrossRef] [PubMed]

6. Smith, B.D.; Morgan, R.L.; Beckett, G.A.; Falck-Ytter, Y.; Holtzman, D.; Teo, C.G.; Jewett, A.; Baack, B.; Rein, D.B.; Patel, N.; et al. Recommendations for the identification of chronic hepatitis C virus infection among persons born during 1945-1965. Morb. Mortal. Wkly. Rep. Recomm. Rep. 2012, 61, 1-32. 
7. Denniston, M.M.; Jiles, R.B.; Drobeniuc, J.; Klevens, R.M.; Ward, J.W.; McQuillan, G.M.; Holmberg, S.D. Chronic hepatitis C virus infection in the United States, National Health and Nutrition Examination Survey 2003 to 2010. Ann. Intern. Med. 2014, 160, 293-300. [CrossRef]

8. Islami, F.; Miller, K.D.; Siegel, R.L.; Fedewa, S.A.; Ward, E.M.; Jemal, A. Disparities in liver cancer occurrence in the United States by race/ethnicity and state. CA Cancer J. Clin. 2017, 67, 273-289. [CrossRef]

9. Kanwal, F.; Kramer, J.R.; Mapakshi, S.; Natarajan, Y.; Chayanupatkul, M.; Richardson, P.A.; Li, L.; Desiderio, R.; Thrift, A.P.; Asch, S.M.; et al. Risk of Hepatocellular Cancer in Patients With Non-Alcoholic Fatty Liver Disease. Gastroenterology 2018, 155, 1828-1837.e1822. [CrossRef]

10. Ha, J.; Yan, M.; Aguilar, M.; Bhuket, T.; Tana, M.M.; Liu, B.; Gish, R.G.; Wong, R.J. Race/ethnicity-specific disparities in cancer incidence, burden of disease, and overall survival among patients with hepatocellular carcinoma in the United States. Cancer 2016, 122, 2512-2523. [CrossRef]

11. Van Thiel, D.H.; Ramadori, G. Non-viral causes of hepatocellular carcinoma. J. Gastrointest. Cancer 2011, 42, 191-194. [CrossRef]

12. Liu, Y.; Wu, F. Global burden of aflatoxin-induced hepatocellular carcinoma: A risk assessment. Environ. Health Perspect. 2010, 118, 818-824. [CrossRef]

13. Mittal, S.; El-Serag, H.B. Epidemiology of hepatocellular carcinoma: Consider the population. J. Clin. Gastroenterol. 2013, 47, S2-S6. [CrossRef]

14. Sahasrabuddhe, V.V.; Gunja, M.Z.; Graubard, B.I.; Trabert, B.; Schwartz, L.M.; Park, Y.; Hollenbeck, A.R.; Freedman, N.D.; McGlynn, K.A. Nonsteroidal anti-inflammatory drug use, chronic liver disease, and hepatocellular carcinoma. J. Natl. Cancer Inst. 2012, 104, 1808-1814. [CrossRef] [PubMed]

15. Bosch, F.X.; Ribes, J.; Diaz, M.; Cleries, R. Primary liver cancer: Worldwide incidence and trends. Gastroenterology 2004, 127, S5-S16. [CrossRef]

16. Signorello, L.B.; Hargreaves, M.K.; Blot, W.J. The Southern Community Cohort Study: Investigating health disparities. J. Health Care Poor Underserved 2010, 21, 26-37. [CrossRef] [PubMed]

17. Signorello, L.B.; Hargreaves, M.K.; Steinwandel, M.D.; Zheng, W.; Cai, Q.; Schlundt, D.G.; Buchowski, M.S.; Arnold, C.W.; McLaughlin, J.K.; Blot, W.J. Southern community cohort study: Establishing a cohort to investigate health disparities. J. Natl. Med. Assoc. 2005, 97, 972-979. [PubMed]

18. US Department of Health Human Services. US Department of Agriculture. 2015-2020 Dietary Guidelines for Americans; 2015. Available online: https://health.gov/sites/default/files/2019-09/2015-2020_Dietary_Guidelines.pdf (accessed on 10 November 2019).

19. Naugler, W.E.; Sakurai, T.; Kim, S.; Maeda, S.; Kim, K.; Elsharkawy, A.M.; Karin, M. Gender disparity in liver cancer due to sex differences in MyD88-dependent IL-6 production. Science 2007, 317, 121-124. [CrossRef]

20. Villa, E. Role of estrogen in liver cancer. Women's Health 2008, 4, 41-50. [CrossRef]

21. Baldissera, V.D.; Alves, A.F.; Almeida, S.; Porawski, M.; Giovenardi, M. Hepatocellular carcinoma and estrogen receptors: Polymorphisms and isoforms relations and implications. Med. Hypotheses 2016, 86, 67-70. [CrossRef]

22. Davila, J.A.; Morgan, R.O.; Shaib, Y.; McGlynn, K.A.; El-Serag, H.B. Diabetes increases the risk of hepatocellular carcinoma in the United States: A population based case control study. Gut 2005, 54, 533-539. [CrossRef] [PubMed]

23. Yuan, J.M.; Govindarajan, S.; Arakawa, K.; Yu, M.C. Synergism of alcohol, diabetes, and viral hepatitis on the risk of hepatocellular carcinoma in blacks and whites in the U.S. Cancer 2004, 101, 1009-1017. [CrossRef]

24. Larsson, S.C.; Wolk, A. Overweight, obesity and risk of liver cancer: A meta-analysis of cohort studies. Br. J. Cancer 2007, 97, 1005-1008. [CrossRef] [PubMed]

25. Calle, E.E.; Rodriguez, C.; Walker-Thurmond, K.; Thun, M.J. Overweight, obesity, and mortality from cancer in a prospectively studied cohort of U.S. adults. N. Engl. J. Med. 2003, 348, 1625-1638. [CrossRef] [PubMed]

26. Setiawan, V.W.; Lim, U.; Lipworth, L.; Lu, S.C.; Shepherd, J.; Ernst, T.; Wilkens, L.R.; Henderson, B.E.; Le Marchand, L. Sex and Ethnic Differences in the Association of Obesity With Risk of Hepatocellular Carcinoma. Clin. Gastroenterol. Hepatol. 2016, 14, 309-316. [CrossRef]

27. Ohki, T.; Tateishi, R.; Shiina, S.; Goto, E.; Sato, T.; Nakagawa, H.; Masuzaki, R.; Goto, T.; Hamamura, K.; Kanai, F.; et al. Visceral fat accumulation is an independent risk factor for hepatocellular carcinoma recurrence after curative treatment in patients with suspected NASH. Gut 2009, 58, 839-844. [CrossRef]

28. Carroll, J.F.; Chiapa, A.L.; Rodriquez, M.; Phelps, D.R.; Cardarelli, K.M.; Vishwanatha, J.K.; Bae, S.; Cardarelli, R. Visceral fat, waist circumference, and BMI: Impact of race/ethnicity. Obesity 2008, 16, 600-607. [CrossRef] [PubMed]

29. LoConte, N.K.; Brewster, A.M.; Kaur, J.S.; Merrill, J.K.; Alberg, A.J. Alcohol and Cancer: A Statement of the American Society of Clinical Oncology. J. Clin. Oncol. 2018, 36, 83-93. [CrossRef] [PubMed]

30. Bagnardi, V.; Rota, M.; Botteri, E.; Tramacere, I.; Islami, F.; Fedirko, V.; Scotti, L.; Jenab, M.; Turati, F.; Pasquali, E.; et al. Alcohol consumption and site-specific cancer risk: A comprehensive dose-response meta-analysis. Br. J. Cancer 2015, 112, 580-593. [CrossRef]

31. Lee, Y.C.; Cohet, C.; Yang, Y.C.; Stayner, L.; Hashibe, M.; Straif, K. Meta-analysis of epidemiologic studies on cigarette smoking and liver cancer. Int. J. Epidemiol. 2009, 38, 1497-1511. [CrossRef]

32. Hall, E.W.; Rosenberg, E.S.; Sullivan, P.S. Estimates of state-level chronic hepatitis C virus infection, stratified by race and sex, United States, 2010. BMC Infect. Dis. 2018, 18, 224. [CrossRef] [PubMed] 
33. Moyer, V.A. Screening for hepatitis C virus infection in adults: U.S. Preventive Services Task Force recommendation statement. Ann. Intern. Med. 2013, 159, 349-357. [CrossRef] [PubMed]

34. Centers for Disease Control and Prevention. CDC Fact Sheet: Viral Hepatitis and Liver Cancer. Available online: https: //www.cdc.gov/nchhstp/newsroom/docs/factsheets/viral-hep-liver-cancer.pdf (accessed on 7 January 2021). 